\title{
Chapter 15 \\ RESEARCH ON WAVE ACTION ON LAKE SHORES AND UNLINED SLOPES OF ARTIFICIAL EARTH STRUCTURES
}

\author{
A. A. Pichoughkin \\ Candidate of technical science \\ The All-Union Scientific Research \\ Institute of Hydrotechnics named for \\ B. E. Vedeneev
}

The construction of big modern hydro-electric plants makes it necessary to create large reservoirs, of which the surface area can be on the order of some hundreds or even thousands square kilometers. As for example, the surface area of the Kuibyshev reservoir is $5600 \mathrm{~km}^{2}$ that one of the Sherbakov reservoir $-4500 \mathrm{~km}^{2}$, of the Stalingrad reser voir $-3470 \mathrm{~km}^{2}$, of Kahovka reservoir $-2155 \mathrm{~km} 2$. The dimensions of reservoirs in plan being so considerable, the waves of $3-3.5 \mathrm{~m}$ height can appear on the water surface. The shoreline of reservoirs created on U.S.S.R. plain rivers exceeds the length of $13000 \mathrm{~km}$. The problem of the protection of the upstream slopes of artificial earth structures and natural shores against wave action is of extreme importance under these conditions.

From the very first days of the existence the reservoir shores are subject to a rather considerable reforming. The destructive force of the surface water waves is the principal factor for the determination of the volume of shore disintegration along the reservoir bottom contour. When combined with landslides, landslips and caving-in of macroporous soils, the surface water waves cause shore movement up to $250 \mathrm{~m}$, measured horizontally, average year movement being 15-20 m (within th first $4-5$ years).

Hundreds of settlements and industrial enterprises are often 1ocated on reservoir shores, which can turn out to be eroded and submergi consequently in some years. So when designing the hydro-electric proje it is necessary to determine the danger zone and to move all the settlements and enterprises out of it; otherwise some adequate measures for protection against submergence must be taken. These problems have assumed ever greater importance wi thin the last few years.

The first knowledges of reservoir shore dynamics relates to thirties in the U.S.S.R. In 1935 the noted soviet hydro-geologist, academician F. P. Savarenski (1)* raised, for the first time, the questi

*See References 


\section{RESEARCH ON WAVE ACTION ON LAKE SHORES AND UNLINED SLOPES OF ARTIFICIAL EARTH STRUCTURES}

about the creating of the scientific basis for predicting the volume of the shore disintegration due to wave action for the reservoirs, projected on the Volga and Dnieper rivers at that time. He himself predicted the volume of shore disintegration for Iljinskaja power plant reservoir on the Lower Dnieper. His work was supplemented later by his disciples and followers: W. A. Shirjamov $(2,3), B . W$. Poljakov $(4), E . G$. Kachugin (5), who proposed some engineering methods of predicting the shore dynamics with a fair degree of accuracy. The above mentioned scientists having analysed the results of a great number of observations carried out on the Volga reservoirs: Ivankovskoje,

Istrinskoje, Himkinskoje, Klaxminskoje and Uglichskoje proposed the design schemes for determining the stable profiles of underwater slopes. In the post-war period the scientific articles by B. A. Pyshkin (6), Gh. S. Solotarev (7), N. E. Kondratjev (8) and others were published. The results of systematical observations carried out on the reservoirs: Kahovskoje, Kuibyshevskoje, Gorkovskoje, Rybinskoje, Tsymljanskoje and others were analysed in. those works.

Apart from storing and systematization of the quantitative data on final shapes and dimensions of underwater slope profiles the attempts are made to determine the effect of the shore-forming factors: the wave energy, the reservoir water level fluctuation, the lithology and the height of above-water shore zone, the initial under-water slope contour as well as the character of water surface undulation. The problem of interaction between the waves and the eroded reservoir bottom and natural laws of shore-forming processes, all as a function of the time, is presently under investigation.

All the problems above are to be solved. For this purpose it is necessary to obtain not only the prototype observational data but some model study data too. The latter should enable to determ ine the effect of each of shore-forming factors separately. That is why in the U.S.S.R. the most serious attention is given to the development of different methods of modeling of wave processes over inclined eroded bottoms an d of movement of non-cohesive soils due to waves. Some achievements obtained have been already published (A. S. Ofitserov; 10). Published data indicate that by carrying out the laboratory tests properly it is possible to ensure the similarity of research on the model and on the prototype with a satisfactory approximation. The Soviet hydraulic engineers and scientists direct their efforts towards the construction of the earth dams and levees with gentle unlined slopes, having the contours similar to that of the old reservoir, lake or sea bottoms. The artificial shallow water parts of the reservoir are to favour the avoiding the expensive concrete and large stones to be used for earth structure slope protection. Some works in this field by B. A. Pyshkin (11), E. S. Tsaits (12), J. E. Gugnjaev (13) enable to build the $0.2 \mathrm{~mm}$ sand levee with unlined upstream 


\section{COASTAL ENGINEERING}

slope 1:20 on Kremenchug reservoir near Cherkassy. In 1958 on the Terek river (Sengeleevskoje) there was built the $7.5 \mathrm{~m}$ earth dam with the protective gravel-rubble prism 1:15 on the upstream slope (14).

As a result of the experimental research carried out by $\mathrm{Hy}-$ draulic Laboratory of the All-Union Scientific Research Institute of Hydrc technics names for B. E. Vedeneev (VNIIG) in 1957-58 the empirical relations are obtained which determine the shapes and the dimensions of stable profiles of artificial earth structures and natural shores composed of non-cohesive soils and subject to the frontal wave action. The frontal wave approaching is often a design value, as:

(1) The earth dams are usually oriented perpendicularly to the river valley direction, so to the longest fetch direction.

(2) The levees are usually built on flat shores, this fact giving almost frontal wave approaching due to refraction in shallow water.

The report by engineer I. J. Popov on some model study data obtained at the Hydraulic Laboratory of VNIIG has been offered to the present Congress.

\section{REFERENCES}

1. F. P. Saxzeenski, To the problem of dammed river shore dis integration. "Hydrogeology and Engineering Geology" N1 (WIMS), Moscow, 1935.

2. W. A. Shirjamov, To the problem of reservoir shore disintegration. Transactions of the Institute of Geological Sciences of the U.S.S.R. Academy of Sciences, Issue 23, EngineeringGeological Series, N2, Moscow, 1940.

3. W. A. Shirjamov, To the methods of the reservoir shore study. Transactions of the Institute of Geological Sciences of the U.S.S.F Academy of Sciences, Issue 43, Engineering-Geological Series, $N$ Moscow, 1940.

4. B. W. Poljakov, Hydrological analysis and designing. Leningrad 1946 .

5. E. G. Kachugin, Abaut the volume of dammed river disintegration. "Gidrotechnicheskoje stroitelstvo", N12, 1951.

6. B. A. Pyshkin, The reservoir shore disintegration dynamics. Edition of the Academy of Sciences of the Ukrainian S.S.R.

7. Gh. S. Solotarev, The reservoir shore disintegration research 


\section{RESEARCH ON WAVE ACTION ON LAKE SHORES AND UNLINED SLOPES OF ARTIFICIAL EARTH STRUCTURES}

carried out by the students of the geological faculty of the Moscow University in 1951 .

8. N. E. Kondratjev, The wave design and the reservoir shore disintegration prediction. Hydrometeorological edition, Leningrad, 195

9. N. E. Kondratjev, Wave energy losses in shallow water. Transac. tions of the State Hydrological Institute, Issue 28, 1951.

10. A. S. Ofitserov, The problem of methods of laboratory research and lineal wave energy losses. Moscow, 1958 .

11. B. A. Pyshkin, Designing of the profiles of the earth hydrotechnic structures with unlined upstream slopes composed of non-cohesive soils. Informational Letter N6, The Institute of Hydrology and Hydrotechnics of the Academy of Sciences of the Ukrainian S.S.R., Kiev, 1956.

12. E.S. Tsaits, Wave action on the slopes composed of noncohesive soils, Kiev, 1958 .

13. J. E. Gugnjaev, Laboratory research of sand slope dynamics . Transactions of the Central Scientific Research Institute of Soil Mechanics and Foundations, Edition N25, 1955.

14. K. N. Sevastjanov, The usage of a wave damping slope for earth dams. Hydrotechnics and Reclamation, N11, 1959.

15. I. J. Popov, The basic planning and design of the earth structures with unlined, stable against wave action slopes. Collected annotations of scientific research on hydrotechnics, finished in 1958 . Gosenergoisdat, M-L, 1959 . 